\title{
Predictions of delamination of a stiffened panel using a cohesive zone model
}

\author{
Peter A. Gustafson* \\ Western Michigan University, Kalamazoo, MI, USA \\ Anthony M. Waas ${ }^{\dagger}$ \\ University of Michigan, Ann Arbor, MI, USA
}

\begin{abstract}
The ability of a finite element cohesive zone model to predict delamination in a stiffened structural component is investigated. A stiffened panel was proposed as a validation test for T650/AFR-PE4/FM680-1 material system cohesive zone parameters that were determined in coupon level tests. Models of the panel were constructed using two methods including the discrete cohesive zone element and the Abaqus $\AA$ COH3D8 element to simulate adhesive failure. The test was found to be insensitive for validation of implicit models. The model and experimental failure loads were found to over-predict the experimental failure load by about 10\%; the displacement at failure over-predicted by a larger margin. The discrepancies are discussed. The coupon level tests for determining the adhesive parameters are also summarized.
\end{abstract}

\section{Introduction}

Modeling of bonded joints is a research area of significant current interest. Although cohesive zone modeling and similar techniques have been used effectively for modeling of coupon level tests, validation of these techniques needs to be expanded to structural level models. This paper pursues validation of a set of cohesive parameters in a simple structural test that exhibits a complex stress state at the adhesive interfaces. The results from the discrete cohesive zone method (DCZM) element ${ }^{1}$ are also compared to results from the commercially available Abaqus cohesive element (COH3D8). ${ }^{2}$

The specimens used for the validation attempt were manufactured from the T650/AFR-PE-4 material system. The AFR-PE4 resin, developed at the Air Force Research Laboratory (Dayton, OH USA), is a polyimide matrix with a glass transition temperature of $360^{\circ} \mathrm{C}$. The system has recently been the subject of an experimental program for material characterization. ${ }^{3}$ It is likely to expand the operating temperatures over which fiber reinforced composite structures are used. Composite components based on AFR-PE4 (and similar resins) are expected to allow a reduction in the mass of the structural supports for ablative and resistive thermal protection systems. In prior work, ${ }^{1,4}$ the T650/AFR-PE- 4 was combined with FM680-1 adhesive and made into coupon level adhesive joint specimens. The adhesive system was characterized in an extensive set of tests that included a novel protocol ${ }^{5}$ to account for the interactions of the parameters $\left(G_{\text {Ic }}, G_{\text {IIc }}, \sigma_{\text {Ic }}, \tau_{\text {IIc }}\right)$ in the experimental outcomes. In this paper, a simple structural test is proposed to validate the measured cohesive zone parameters. Validation is the primary focus of this paper, however, some of the details of the prior work are re-reported for clarity and completeness. Although adhesive system characterization was completed at temperatures in the range $20-350{ }^{\circ} \mathrm{C}$, the validation attempt is limited to the $20^{\circ} \mathrm{C}$ case due to limited material availability.

The values for Mode I and Mode II critical energy release rates $\left(G_{\text {Ic }}, G_{\text {IIc }}\right)$ and Mode I and Mode II cohesive strengths $\left(\sigma_{\text {Ic }}, \tau_{\text {IIc }}\right)$ were computed as a function of temperature from experimental results. The Mode III parameters are assumed to be identical to Mode II, thus four cohesive parameters are used. The

\footnotetext{
*Assistant Professor, Department of Mechanical and Aeronautical Engineering, Member, AIAA

${ }^{\dagger}$ Professor, Department of Aerospace Engineering, Associate Fellow, AIAA

Copyright (C) 2010 by Peter A. Gustafson. Published by the American Institute of Aeronautics and Astronautics, Inc. with permission.
} 
four parameters and an assumed triangular traction law ${ }^{6}$ can be used with the DCZM or the Abaqus® COH3D8 cohesive element to model bond line failure in structures made from T650/AFR-PE-4/FM680-1.

\section{A. Organization}

The organization of the paper follows. The manufacturing of specimens is described in section II. In section III, double cantilever beam (DCB) experiments and analysis of $G_{\text {Ic }}$ are summarized from the prior work. ${ }^{1}$ Then in section IV, the Mode I strength is evaluated using a button peel stress (BPS) test. Subsequently in section V, the critical energy release rate in Mode II $\left(G_{\text {IIc }}\right)$ is determined by the compliance calibration (CC) analysis technique for the end notch flexure (ENF) test. In section VI, the Mode II cohesive strength $\left(\tau_{\text {IIc }}\right)$ is determined based on single lap joint (SLJ) experimental results. A surrogate model based mapping procedure $^{5}$ is used to determine appropriate values of $\tau_{\text {IIc }}$. This allows the interactions between $\tau_{\text {IIc }}, G_{\text {IIc }}$, and $G_{\text {Ic }}$ to be properly accounted so that the resulting cohesive zone parameters are appropriate for all the coupon level tests as well as structures composed of the T650/AFR-PE-4/FM680-1 material system. This novel accounting procedure has not been previously demonstrated. Finally, the validation test and model are described in section VII.

Due to ITAR restrictions on the subject materials, some detail is excluded from this paper. The measured material parameters are presented as normalized quantities. Some other properties and manufacturing details are omitted. All numerical values and plots are normalized by the mean of the Mode I inverse method critical energy release rate at room temperature $\left(G_{\mathrm{Ic}}^{\mathrm{i} \text { ave }}(T=20)\right)$.

$$
\begin{aligned}
& \bar{G}_{\mathrm{Ic}}^{\mathrm{a}}=\frac{G_{\mathrm{Ic}}^{\mathrm{a}}}{G_{\mathrm{Ic}}^{\mathrm{i} a v e}(T=20)}, \quad \bar{G}_{\mathrm{Ic}}^{\mathrm{i}}=\frac{G_{\mathrm{IC}}^{\mathrm{i}}}{G_{\mathrm{Ic}}^{\mathrm{i} a v}(T=20)}, \quad \bar{G}_{\mathrm{IIc}}=\frac{G_{\mathrm{IIc}}}{G_{\mathrm{Ic}}^{\mathrm{i} v e}(T=20)}, \\
& \bar{\sigma}_{\mathrm{Ic}}=\frac{\sigma_{\mathrm{Ic}}}{G_{\mathrm{Ic}}^{\mathrm{a} a v e}(T=20)}, \quad \bar{\tau}_{\mathrm{IIc}}=\frac{\tau_{\mathrm{IIc}}}{G_{\mathrm{Ic}}^{\mathrm{i} a \mathrm{ave}}(T=20)}, \quad \bar{P}=\frac{P}{G_{\mathrm{Ic}}^{i \text { ave }}(T=20)} \text {. }
\end{aligned}
$$

The experiments used to determine these parameters are approximately two-dimensional, therefore, $P$ in equation 1 is reported as the line load (the load per unit depth). After normalization, $\bar{P}, G_{\text {Ic }}$, and $G_{\text {IIc }}$ are unit-less. $\sigma_{\text {Ic }}$ and $\tau_{\text {IIc }}$ have units of $\mathrm{m}^{-1}$.

\section{Geometry selection and specimen preparation}

The assumed triangular traction law for the adhesive requires four parameters $\left(G_{\text {Ic }}, G_{\text {IIc }}, \sigma_{\text {Ic }}, \tau_{\text {IIc }}\right)$; each parameter requires one set of experiments to determine its value. The traction law is graphically depicted in figure 1. Although several experimental methods could be used for each parameter, the four adhesive characterization experiments in this paper are the DCB test, the BPS test, the ENF test, and the SLJ test. The specimens for these tests are described in this section.

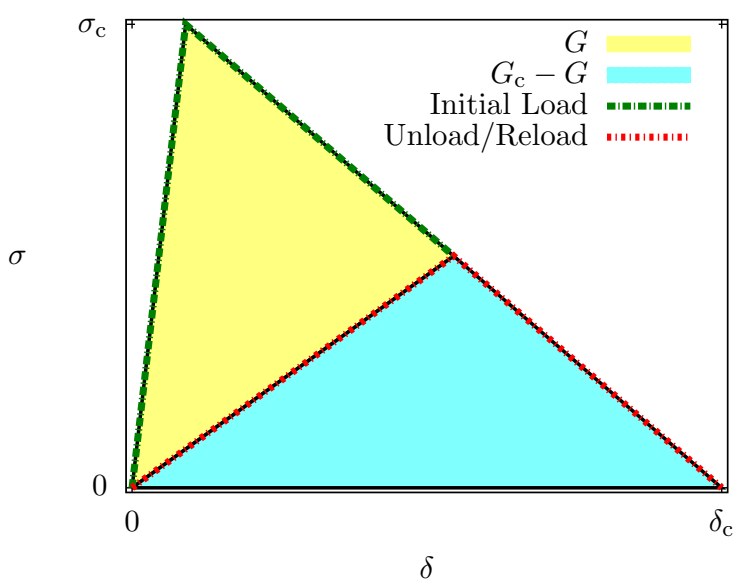

Figure 1: Assumed traction law for the inverse model. $\sigma$ represents the stress in Mode I, Mode II, or Mode III; $\delta$ represents the relative displacement or separation in each mode.

The pre-preg material, T650/AFR-PE-4, was donated by Cytec, Inc. The adhesive, FM680-1, was 
donated by Goodrich, Inc. Due to the cost associated with each material, a limited quantity was available. As a result, a principle consideration in sizing each specimen was material consumption. To conserve material, all laminates were constructed of four plies (except the BPS specimen laminate).

\section{A. Manufacturing of DCB, ENF, and SLJ specimens}

The DCB, ENF, and SLJ specimens were prepared in batches using bidirectional woven T650 lamina preimpregnated with AFR-PE-4. The plies were arranged by hand layup into $[0,90]_{s}$ laminates and cured in a Wabash model 30-1515 press. The multi-step curing cycle followed the manufacturer's recommendation $^{3}$ as closely as possible with modifications required for hot press operations. ${ }^{\mathrm{a}}$ The cured laminated plate had two distinct surface textures referred to as smooth (released from the stainless steel mold plate) and rough (released from the peel ply/fiberglass batting). The cured plate geometry was approximately $315 \times 315 \times 1.25 \mathrm{~mm}$.

Following the cure cycle, each laminate was cut into four smaller plates of approximately $155 \times 155 \times 1.25 \mathrm{~mm}$. This plate size set the total length of the DCB (and ENF) specimens. All specimens were prepared with adherends obtained from the same laminate. Prior to any bonding, the plates were lightly roughened with 200 grit sandpaper and cleaned with acetone.

For the DCB and ENF specimens, the small plates were bonded as stacked pairs such that the adhesive covered a portion of the interface (sufficient to yield the desired initial crack length). For the SLJ specimens, two plates were bonded to overlap by $25.4 \mathrm{~mm}$. Stainless steel mold plates supported the free ends of the SLJ adherends. In each assembly, the bonding was completed using Cytec FM680-1 adhesive film (an adhesive carried on a fiberglass scrim). The adhesive was cured during a separate step in the hot press. ${ }^{b}$ The assemblies were arranged so that the adhesive layer was in contact with one rough and one smooth side of the adherends. A $50 \mu \mathrm{m}$ film sheet of Kapton (coated with Loctite 770-NC mold release) was inserted between the DCB and ENF adherends to initiate a crack.

Subsequent to curing, the assembly was post-cured according to the manufacturer's recommended cycle. For the SLJ specimens, the free adherend ends were cut roughly in half and used as the doubling section between the wedge grips. ${ }^{c}$ The nominal size of the SLJ notch $\left(l_{\mathrm{n}}\right)$ was $2 \mathrm{~mm}$. In the last step of the DCB, ENF, and SLJ manufacturing process, the edges of the bonded plates were trimmed and individual specimens were cut from the remaining material.

\section{B. The DCB specimen}

The geometry of the DCB specimen is shown schematically in figure 2(a). Figure 3(a) shows a typical DCB test. After trimming, the nominal length $(l)$ of the DCB specimen was $130 \pm 3 \mathrm{~mm}$ and the nominal width (b) was $20 \pm 0.3 \mathrm{~mm}$. The nominal thickness $(h)$ of the adherends was $1.25 \pm 0.05 \mathrm{~mm}$.

The position of the Kapton film (i.e. the position of the initial crack tip) for the DCB specimen was $20 \pm 2 \mathrm{~mm}$ relative to the hinge. Due to the high temperatures to which the joints were subjected, the hinges were attached with \#4-40 machine screws. Holes were drilled in the specimens to accommodate these screws. The hole size was set so that the conical heads of the machine screws were approximately flush with the inside surfaces of the DCB specimen (the screw shank protruded outward from the specimen centerline). The resulting hinged specimen (as tested) had less than $0.5 \mathrm{~mm}$ of initial displacement caused by the screw heads.

\section{The ENF specimen}

The DCB geometry (described in section II) was found to be appropriate for the ENF specimen; therefore, it was selected. The ENF geometry conforms to the guidelines proposed ${ }^{7}$ for the upcoming ENF ASTM International (ASTM) standard. The geometry of the ENF specimens are shown schematically in figure 2(b). Figure 4(a) shows a typical ENF specimen at several visual scales.

\footnotetext{
aThe details of the curing cycle are ITAR restricted, contact the manufacturer for additional detail.

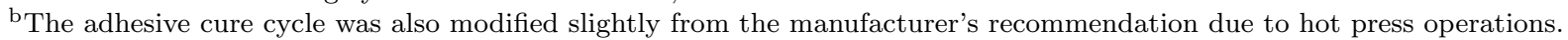

${ }^{\mathrm{c}}$ The doubling was initially held in place by J-B Weld epoxy, however, at high temperatures this epoxy broke down. Although this required care in gripping, there were no significant adverse effects since the two adherends (in the doubling section) did not slip relative to each other.
} 


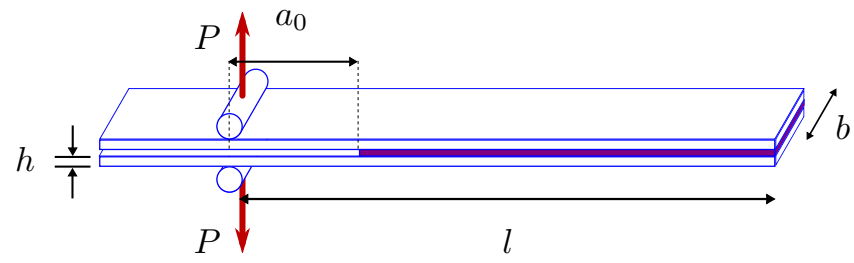

(a) DCB specimen geometry

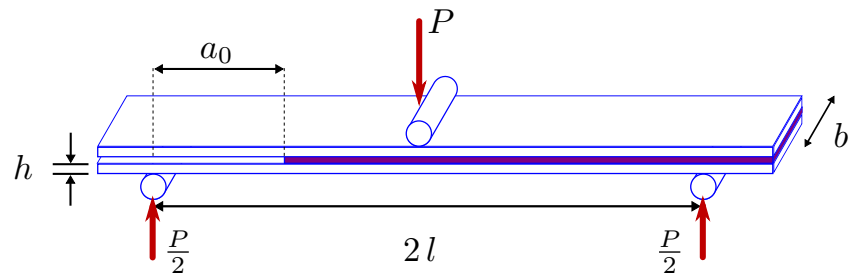

(b) ENF specimen geometry

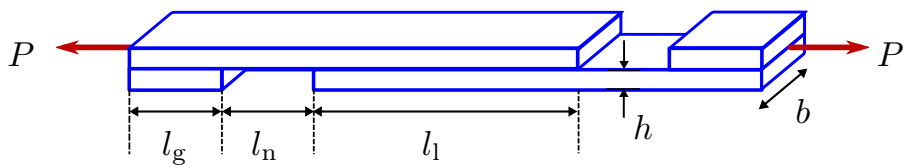

(c) SLJ specimen geometry

Figure 2

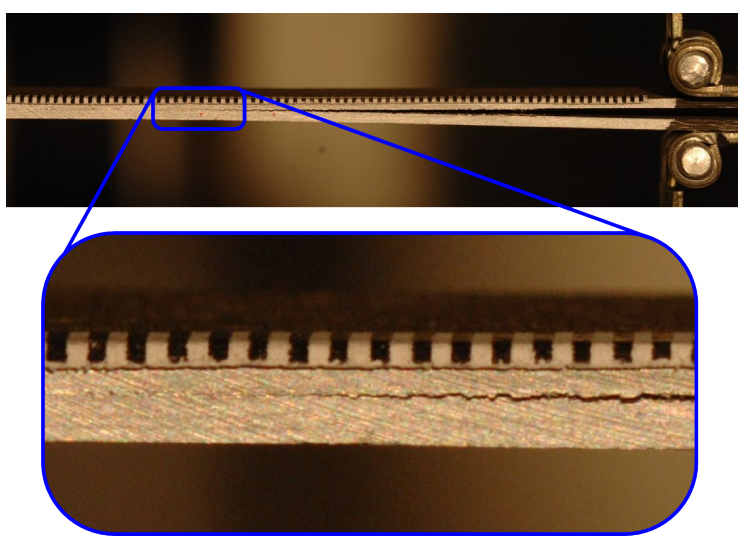

(a) Typical DCB image used for analysis of apparent crack propagation.

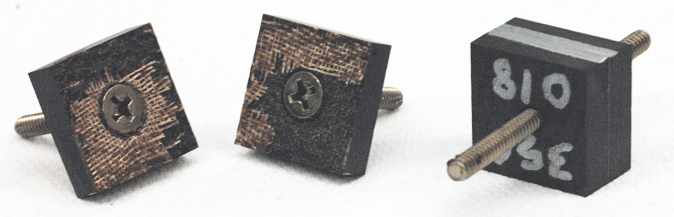

(b) Typical BPS specimens before and after the experiment

Figure 3 


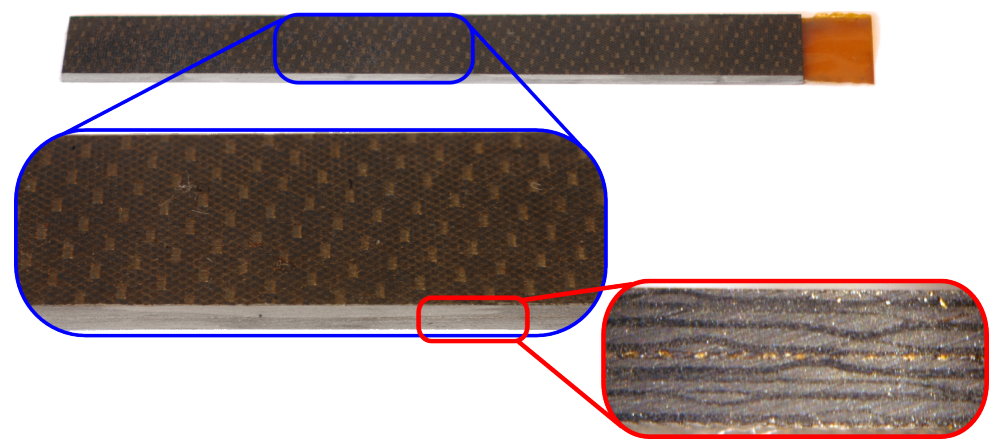

(a) A ENF specimen shown at different scales

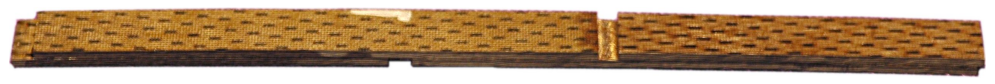

(b) A SLJ specimen

Figure 4: Typical ENF and SLJ specimens

\section{The SLJ specimen}

The objective of the SLJ test is to determine the Mode II cohesive strength $\left(\tau_{\text {IIc }}\right)$ for use in the DCZM element traction law. Although the ASTM recommends a specific geometry for the SLJ test, initial tests showed that the failure load would exceed the load frame capacity (for the available Instron model 4201 electromechanical load frame with an Instron model 3119 temperature chamber).

To select an appropriate alternative geometry, an analytical design of experiments (DOE) was completed to assess specimen geometric variables. The base finite element (FE) model was generated using parameters derived from initial experimental data. Notch length $\left(l_{\mathrm{n}}\right)$ was found to have a negligible effect on the output. This was confirmed by a thorough sensitivity analysis. ${ }^{5}$ Since the specimen geometry was required to depart from the ASTM recommendation, the value of $l_{\mathrm{n}}$ was reduced to limit material consumption. The DOE and preliminary experiments indicated that a specimen width of $12.5 \mathrm{~mm}$ would be appropriate over the entire range of temperatures, therefore, it was selected as the nominal specimen width.

The geometry of the SLJ specimens are shown schematically in figure 2(c). A typical SLJ specimen is shown in figure 4(b). After trimming, the nominal length $(l)$ of the ENF specimen was $130 \pm 3 \mathrm{~mm}$ and the nominal width $(b)$ was $20 \pm 0.3 \mathrm{~mm}$. The nominal width of the SLJ specimen was $12.5 \pm 0.3 \mathrm{~mm}$. The nominal thickness $(h)$ of the ENF/SLJ specimen adherends were $1.25 \pm 0.05 \mathrm{~mm}$.

\section{E. The BPS specimen}

In contrast to the other specimen types, the BPS specimens were cut from a sixteen ply laminate provided by Pratt \& Whitney Corporation ${ }^{\mathrm{d}}$. The laminate allowed for additional adherend thickness and provided a robust hole/countersink structure that was able to withstand the experimental loads. As with the other specimen types, manufacturing constraints dictated the geometry. Only one plate was available as a source for BPS specimens. The required number of BPS experiments dictated a minimum of sixteen specimens be manufactured from the plate (with additional specimens for pretesting).

There were several requirements in establishing the specimen geometry shown in figure 3(b). First, an accurate estimate of the adhesive surface area is required for computation of the peel stress. The uncertainty associated with adhesive spew precluded a geometry where the adhesive only covered a small portion of the adherend surface. Second, the cured adhesive layer is thin and prevents the insertion of a gripping fixture in a gap formed by the adhesive thickness. Third, the extreme temperatures during the experiment (and the high strength of FM680-1 at those temperatures) cause reliability concerns for any fixture attached by bonding. In view of the constraints, a machine screw with a tapered head was inserted through a counter-sunk hole in the center of each square adherend. The screws (shown in figure 3(b)) were found to be an effective fixture. The square specimen was found to meet manufacturing constraints. Initial testing showed that fast fracture

\footnotetext{
${ }^{\mathrm{d}}$ Courtesy of Dr. R. A. Naik.
} 
was the failure mode of the BPS specimen. Fast fracture is an indication that $\sigma_{\text {Ic }}$ is the dominant parameter at failure, therefore, the specimen geometry was accepted. ${ }^{\mathrm{e}}$

The 16 ply laminate was cut into square specimens with $20 \mathrm{~mm}$ (nominal) sides. The nominal laminate thickness was $5.7 \pm 0.03 \mathrm{~mm}$. A $4 \mathrm{~mm}$ diameter hole was drilled into each square to accommodate the machine screw that was used as a fixture. The hole was countersunk until the screw head was below flush. The squares, in pairs, were then lightly roughened with the 200 grit sandpaper on the bonding face and cleaned with acetone. Prior to assembly, the \#6-32 machine screws were coated with six coats of Freekote $770 \mathrm{NC}$ mold release to ensure minimal adhesion in the event of adhesive spew. ${ }^{\mathrm{f}}$ FM680-1 adhesive squares were placed over the bonding surfaces and a hole was cut in the adhesive scrim. The machine screw was passed through the adhesive so that the screw head remained free of adhesive. The faces of the adherends and the screw heads were aligned prior to the adhesive curing cycle.

\section{Experimental determination of $G_{\text {Ic }}$}

\section{A. The DCB experimental protocol}

The DCB experiments were completed on an Instron model 5585 electro-mechanical loading frame. The specimens, including grips, were enclosed in an Instron model 3119 environmental chamber and brought to the specified temperatures $\left(T=\{20,150,250,350\}{ }^{\circ} \mathrm{C}\right)$. Four specimens were tested at each temperature. The air inside the environmental chamber was stirred constantly to ensure uniformity; the temperature was maintained to $\pm 2{ }^{\circ} \mathrm{C}$. A minimum of 20 minutes was allowed to obtain thermodynamic equilibrium after reaching the specified temperature. Prior to the measured load-displacement cycle, a natural crack was initiated by enforcing a cross-head displacement of $5 \mathrm{~mm}$ while at temperature. Therefore, the initial crack length $\left(a_{0}\right)$ was determined by this initial enforced displacement. The DCB specimens were subsequently loaded via displacement control at $5 \mathrm{~mm} / \mathrm{min}$. An escalating sawtooth displacement pattern was prescribed. The bounding displacements were: $w_{\text {tip }}=[0,8,0,11,0,14,0,17,0,20] \mathrm{mm}$. Load and displacement measurements were acquired at a minimum of $10 \mathrm{~Hz}$. Photographic images were taken at 5 second intervals to determine the apparent crack position.

\section{B. Experimental results $G_{\text {Ic }}$}

A set of typical load-displacement curves are shown in figure 5. The curves were numerically integrated to determine the total work done during each displacement cycle. Two methods were used ${ }^{1}$ to determine $G_{\text {Ic }} ;$ a method based on work and crack area and an inverse numerical method. The normalized results are shown in figure 6 .

\section{Experimental determination of $\sigma_{\text {Ic }}$}

The critical peel stress $\left(\sigma_{\text {Ic }}\right)$ is the second parameter in the traction law and is determined by the BPS test. An Instron model 4201 electromechanical frame was used to load the specimens; an Instron model 3119 environmental chamber enclosed the specimen and controlled temperature to the tolerances described in section III. Four BPS failure tests were completed at each of four temperatures.

\section{A. The BPS experimental protocol}

The BPS experimental protocol began with the specimens being placed into the wedge grips so that the machine screw threads and the knurled wedge grip faces interlocked. Very little clamping force was required to prevent slippage during the test, therefore, no compression beyond the natural compression of the wedge was required. The outer face of the specimen was flush with the tips of the wedge grips.

The specimens were loaded in displacement control at $0.5 \mathrm{~mm} / \mathrm{min}$ until fracture. High speed video was taken of the fracture event. The video showed that the initial fracture event completely severed the interface in most specimens. In the remaining specimens (usually at high temperature), the crack propagated over

eNo standard BPS specimen is currently available for composite materials. The current specimen is believed to yield an appropriate value for $\sigma_{\text {Ic }}$. Results with a variant of the BPS have been reported by Sun ${ }^{8}$ who examined a steel/adhesive/steel material system. The development of a standardized procedure and specimen would add confidence to the results.

${ }^{\mathrm{f}}$ Post-test inspection revealed that there was no significant adhesive spew over the screw head. 


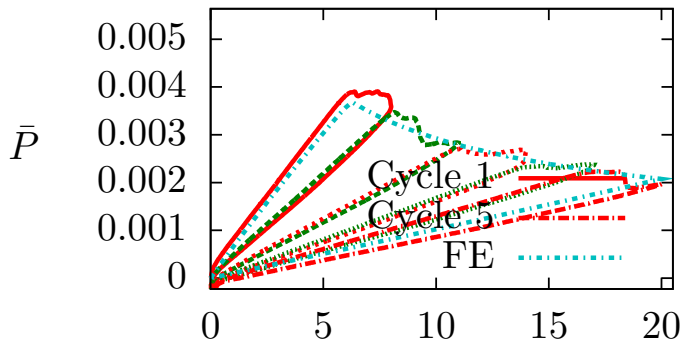

Crosshead Displacement (mm)

(a) $\mathrm{T}=20^{\circ} \mathrm{C}$

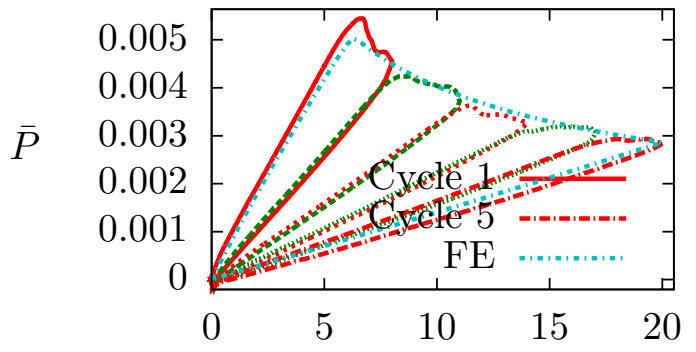

Crosshead Displacement (mm)

(c) $T=250{ }^{\circ} \mathrm{C}$

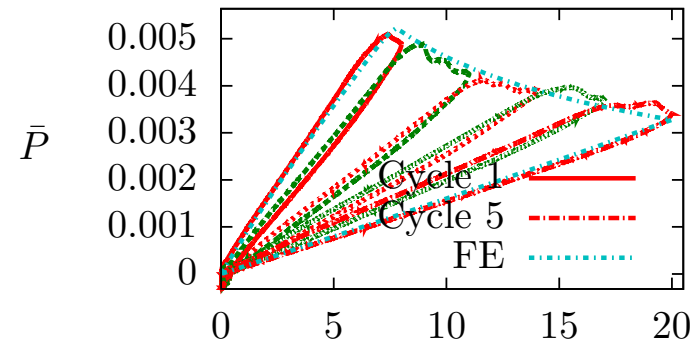

Crosshead Displacement (mm)

(b) $T=150{ }^{\circ} \mathrm{C}$

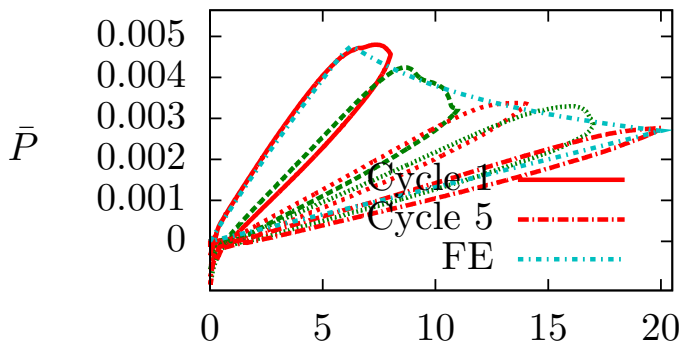

Crosshead Displacement (mm)

(d) $\mathrm{T}=350^{\circ} \mathrm{C}$

Figure 5: Typical normalized load-displacement and inverse model results for T650/AFR-PE-4/FM680-1 DCB specimens.

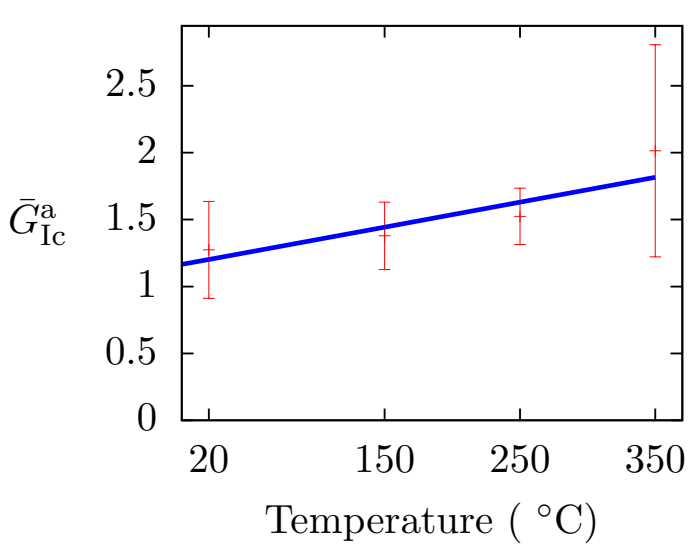

(a) Distribution of $\bar{G}_{\text {Ic }}^{\text {a }}$

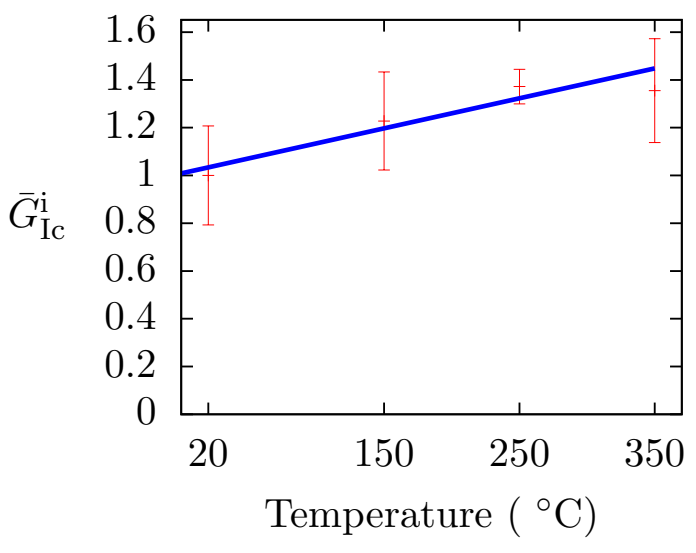

(b) Distribution of $\bar{G}_{\mathrm{Ic}}^{\mathrm{i}}$

Figure 6: Normalized $\bar{G}_{\text {Ic }}$ results as a function of temperature. The error bars represent \pm 1 standard deviation from the local mean. 
the majority of the interface while leaving a few strands of fiberglass scrim bridging the crack. This result was at least partially due to increased friction in the wedge grips at high temperature. (The grips had to be knocked free with a malleable hammer at the conclusion of these tests.) Since the specimens were loaded in displacement control and friction prevented complete severance, the bridging scrim was deemed insignificant relative to the total surface area. For the purposes of data reduction, all specimens were considered to have failed instantly. Typical normalized load-displacement results for the BPS experiments are shown in figure 7. The critical stress values $\left(\sigma_{\text {Ic }}\right)$ were calculated using:

$$
\sigma_{\text {Ic }}=\frac{P_{\text {fail }}}{A_{\mathrm{BPS}}} .
$$

In equation 2, $P_{\text {fail }}$ is the failure load and $A_{\mathrm{BPS}}$ is the bonded surface area of the BPS specimen. In order to accurately account for the screw head and it's reduction of the bonded surface area, $A_{\mathrm{BPS}}$ was determined through photographic evaluation of the failed specimen. The evaluation consisted of a (manually guided) image threshold of a surface image which allowed the pixels of the surface area to be counted. A linear ruler was included in the photograph to establish the pixel density, from which the area was calculated. A sample photograph from this process is shown in figure 8. The figure also illustrates a typical failure; the scrim was found to be distributed to both the smooth and rough sides of the specimen.

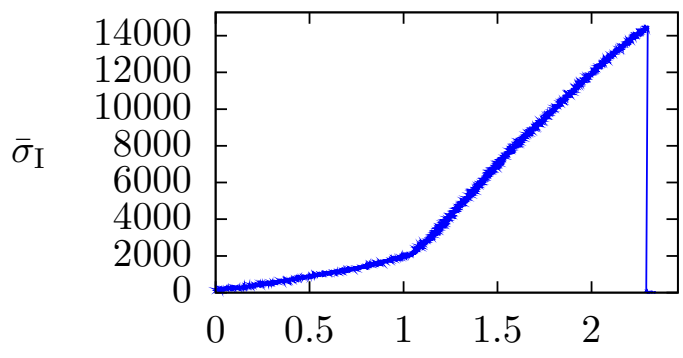

Crosshead Displacement ( $\mathrm{mm})$

(a) $\mathrm{T}=20{ }^{\circ} \mathrm{C}$

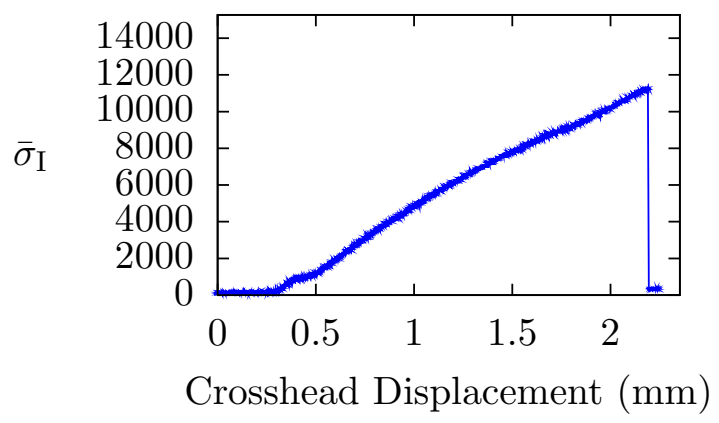

(c) $\mathrm{T}=250^{\circ} \mathrm{C}$

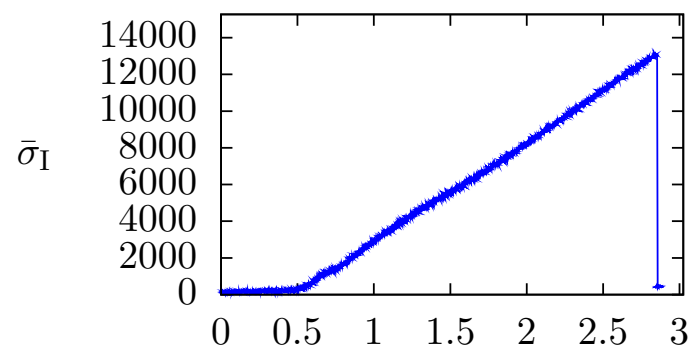

Crosshead Displacement (mm)

(b) $\mathrm{T}=150^{\circ} \mathrm{C}$

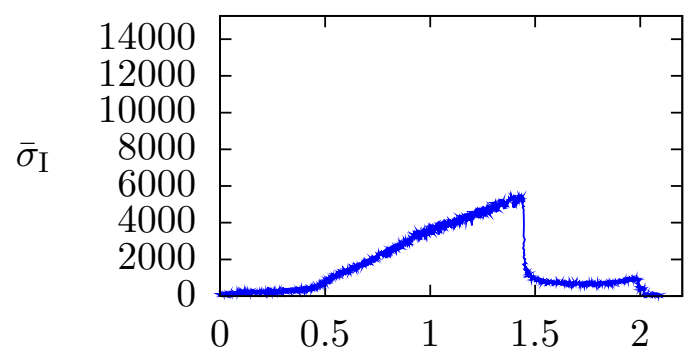

Crosshead Displacement (mm)

(d) $\mathrm{T}=350^{\circ} \mathrm{C}$

Figure 7: Typical normalized stress-displacement for BPS specimens

\section{B. The BPS results for $\sigma_{\text {Ic }}$}

The distributions of $\sigma_{\text {Ic }}$ are shown as a function of temperature in figure 9 . Unlike $G_{\text {Ic }}$, the value of $\sigma_{\text {Ic }}$ decreases with temperature. Whereas increased plasticity was a likely cause of increased $G_{\text {Ic }}$ at higher temperatures, it is also a likely cause of decreased $\sigma_{\text {Ic }}$. The variability of $\sigma_{\text {Ic }}$ is similar in relative magnitude to variability of $G_{\text {Ic }}$ (approximately $20 \%$ of the mean value). When combined with the $G_{\text {Ic }}$ results in section III, the Mode I parameters are now defined. 


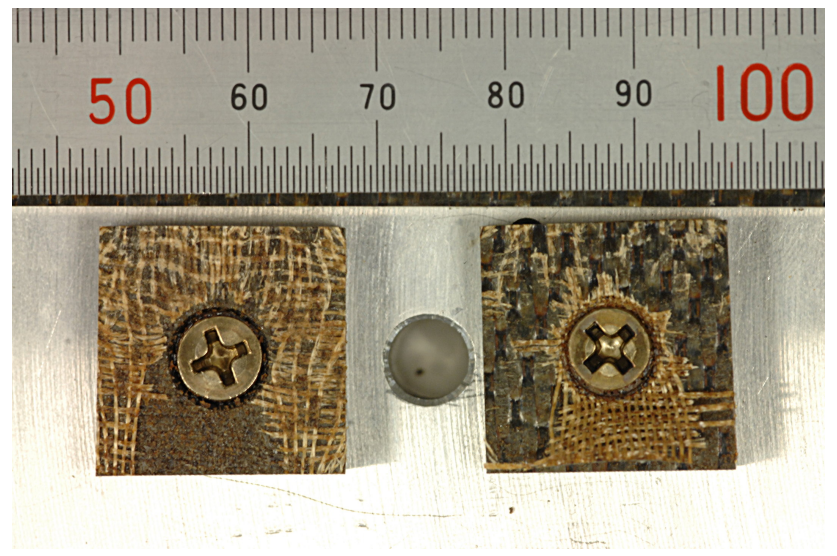

Figure 8: Typical photograph used to determine the BPS bonded area

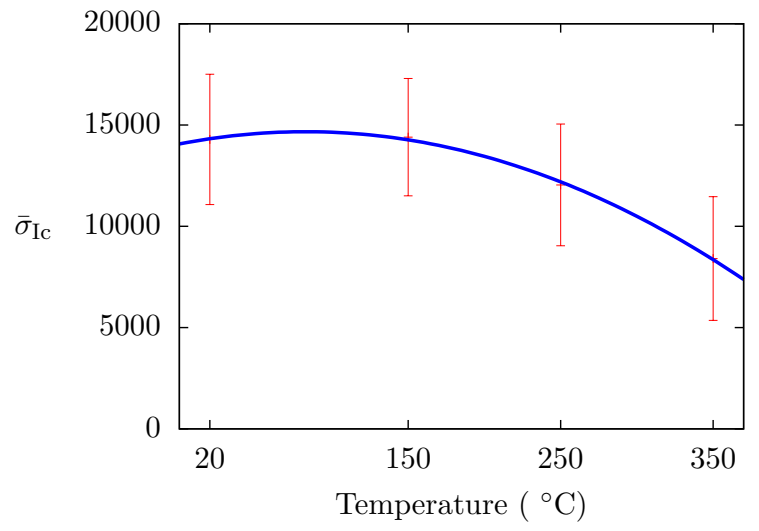

Figure 9: Distribution of $\bar{\sigma}_{\text {Ic }}$ as a function of temperature 


\section{Experimental determination of $G_{\text {IIc }}$}

The Mode II critical energy release rate $\left(G_{\text {IIc }}\right)$ is the third parameter in the traction law for T650/AFRPE-4/FM680-1 and is considered next. It is computed from the results of the ENF test. An Instron model 4201 electromechanical frame was used to load the specimens and an Instron model 3119 environmental chamber enclosed the specimen and controlled temperature to $\pm 2{ }^{\circ} \mathrm{C}$.

\section{A. The ENF experimental protocol}

The ENF experiments were completed according to the geometric and data reduction recommendations described by Davidson and Sun. ${ }^{7}$ Four specimens were tested at each of the four temperatures. The specimen geometry was almost identical to the DCB specimens except for the initial crack position. In the ENF specimen, crack position was referenced to the roller support. The total span $(2 l)$ was $104 \mathrm{~mm}$ and the support rollers had a diameter of $6.35 \mathrm{~mm}$. The loading roller was $12.7 \mathrm{~mm}$ in diameter.

A compliance calibration was completed for each specimen with a curve fitting equation, $:^{7}$

$$
C(a)=A+m a^{3} .
$$

$C(a)$ is the specimen compliance; $A$ and $m$ are curve fit coefficients. The nominal crack fractions for the calibration were $\{0.4,0.5,0.6,0.7,0.8\}$ and the cross-head displacement was taken to $2.0 \mathrm{~mm}$ at all temperatures except $350{ }^{\circ} \mathrm{C}$. At $350{ }^{\circ} \mathrm{C}$, the cross-head displacement during calibration was limited to $1.5 \mathrm{~mm}$ to ensure no damage would occur. The nominal crack tip was determined by physical examination of both edges of the ENF specimen (there is significant uncertainty about the actual crack position due to the possibility of jagged crack fronts $\left.{ }^{9}\right)$.

The last calibration cycle was applied at a crack fraction of 0.5. Thereafter, the loading was continued from that point past initial crack propagation. After initial propagation was observed during the experiment, the specimen was then partially unloaded to allow additional loading cycles. In this way, the same specimen was used to achieve at least three separate values of $G_{\text {IIc }}$ for each specimen. These values were averaged prior to inclusion in the data set used to generate figure 10(a). The averaging technique is meant to provide a more representative value of $G_{\text {IIc }}$ for the whole specimen.

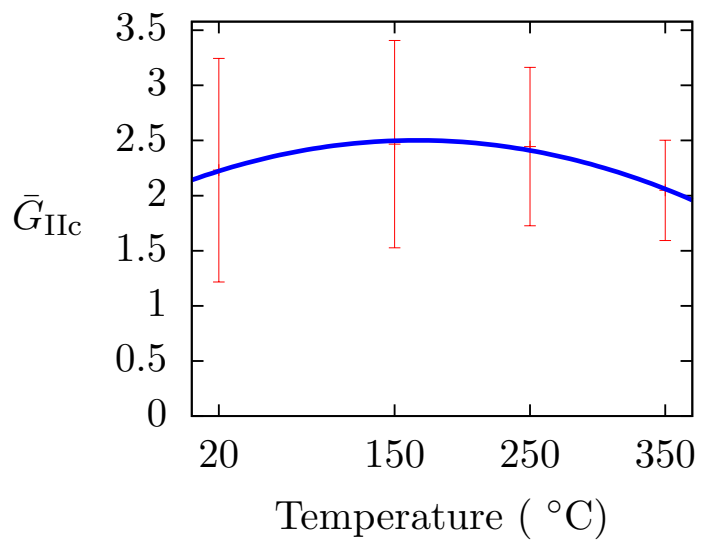

(a) Distribution of $\bar{G}_{\text {IIc }}$

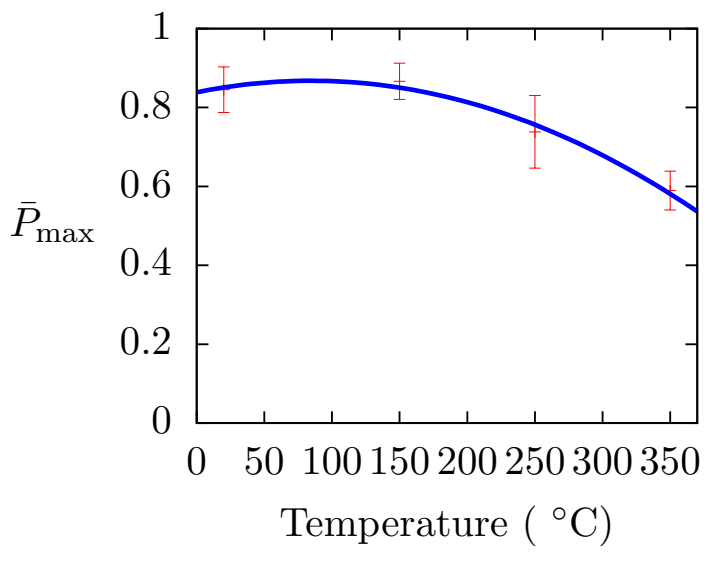

(b) Distribution of SLJ $\bar{P}_{\max }$

Figure 10: Normalized ENF and SLJ results as a function of temperature

\section{B. The ENF results for $G_{\text {IIc }}$}

Typical normalized load-displacement curves for the ENF test are shown in figure 11. The compliance calibration cycles are apparent in the figures; there are several curves at different nominal crack lengths shown. Additionally, the loading and unloading cycles are also readily visible in the plots. The ENF experiments exhibited linear load-unload behavior in all specimens except at $350{ }^{\circ} \mathrm{C}$. 


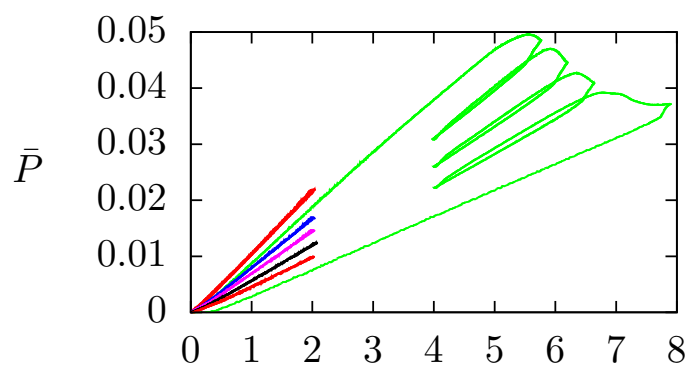

Crosshead Displacement (mm)

(a) $\mathrm{T}=20^{\circ} \mathrm{C}$

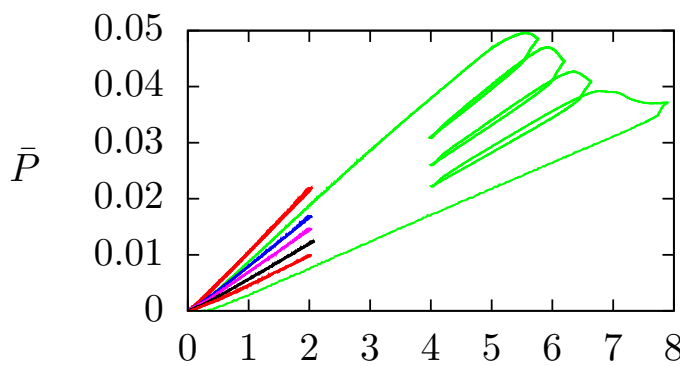

Crosshead Displacement (mm)

(c) $\mathrm{T}=250^{\circ} \mathrm{C}$

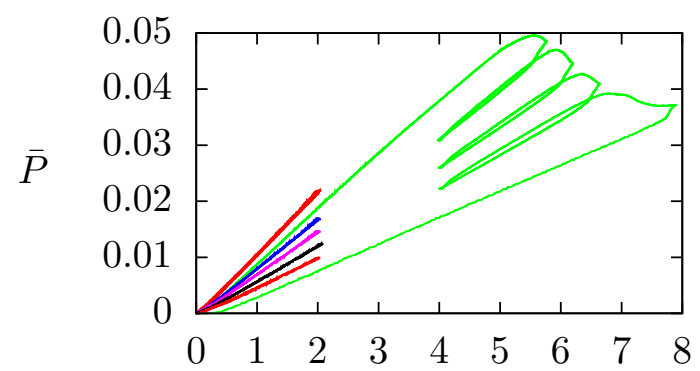

Crosshead Displacement ( $\mathrm{mm}$ )

(b) $T=150{ }^{\circ} \mathrm{C}$

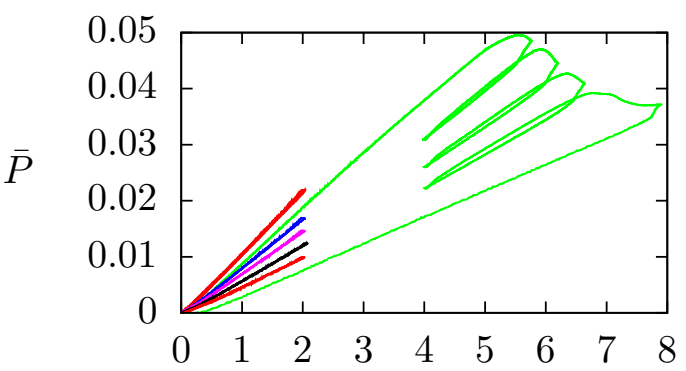

Crosshead Displacement (mm)

(d) $T=350{ }^{\circ} \mathrm{C}$

Figure 11: Typical normalized load-displacement for ENF specimens. In addition to the ENF cycle, the CC steps are plotted for different initial crack lengths. 
The computed values of $G_{\text {IIc }}$ are shown in figure 10(a). Comparing figure 10(a) with the corresponding results for $\bar{G}_{\text {Ic }}$ and $\bar{\sigma}_{\text {Ic }}$ in figures $6(\mathrm{~b})$ and 9 , it is apparent that the variability in $G_{\text {IIc }}$ is far greater than for $G_{\text {Ic }}$ and $\sigma_{\text {Ic }}$. This significant variability presents numerous challenges to be addressed in a later work. It is likely that the nature of the composite weave, with pockets of matrix material, contributes to the variability in the ENF results. It is possible that these pockets have greater effect on the ENF experiments than the other experiments. Another possible source of variability is the rate of crack advance. ${ }^{8,9}$ "Stick-slip" crack advance behavior was observed in some specimens, therefore, rate effects cannot be discounted. Despite the variability, the mean value of $G_{\text {IIc }}$ is fairly consistent over the entire temperature range. The critical energy release rate in Mode II is approximately double the value in Mode I.

\section{Experimental determination of $\tau_{\text {IIc }}$}

The final parameter in the adhesive traction law is the cohesive strength in Mode II $\left(\tau_{\text {IIc }}\right)$. It is determined by careful interpretation of the single lap joint test.

\section{A. The SLJ experimental protocol}

The single lap joint test was completed for four specimens at four temperatures. Specimens were prepared as reported in section II. The wedge grip assembly was completed outside the oven and then placed into the load frame (external assembly minimized heat losses during high temperature tests). Unlike the BPS specimen, the relatively smooth surfaces of the adherends in the SLJ test caused difficulty with slippage in the wedge grips. In addition to the natural compression caused by the wedges, the knurled grip faces were compressed into the specimen. After the assembly reached the desired temperature, it was allowed to equilibrate for 20 minutes. Subsequently, displacement control was enforced at $0.5 \mathrm{~mm} / \mathrm{min}$ until failure occurred.

\section{B. The SLJ results for $\tau_{\text {IIc }}$}

Representative normalized load-displacement curves for the SLJ test are shown in figure 12. After an initial displacement where wedge settling occurred, the load scaled linearly with displacement until failure. A few specimens, distributed randomly over the temperatures, exhibited a small but noticeable crack advance with associated load drop prior to failure. An example of this is the $350{ }^{\circ} \mathrm{C}$ specimen in figure 12 . One specimen (at $250{ }^{\circ} \mathrm{C}$, highlighted in figure 12) was observed to slip in the grips, however, this only had the effect of unloading the specimen slightly. Loading was able to continue through the slippage up to a failure point. The slope of the load-displacement curve did not change appreciably after the slippage, therefore it was deemed to have negligible effect on the experiment. In two of the experiments (one at $20{ }^{\circ} \mathrm{C}$ and one at $350{ }^{\circ} \mathrm{C}$ ), the failure was not entirely in the adhesive or at the adherend/adhesive interface. The specimens exhibited partial $\left(20^{\circ} \mathrm{C}\right)$ or total $\left(350^{\circ} \mathrm{C}\right)$ interlaminar failure in the adherend. As a result, the values from these experiments are excluded from the results plotted in figure 10(b).

It is known ${ }^{5}$ that the SLJ test cannot be used in isolation to determine appropriate values for $\tau_{\text {IIc }}$. To map the experimental results to a usable set of parameters for $\tau_{\text {IIc }}$, the distribution of peak line loads was calculated at each temperature. This distribution is shown in figure 10(b). Using a surrogate model ${ }^{5}$ as an inverse model, contour lines were established in $\left(G_{\text {IIc }}, \tau_{\text {IIc }}\right)$ space from the values of the $\bar{P}_{\text {max }}$ distributions. In the surrogate, $G_{\text {IIc }}$ and $\tau_{\text {IIc }}$ were allowed to vary while the remaining variables were fixed at their experimental nominal values. ${ }^{\mathrm{g}}$

The inverse equivalent contours of $\bar{P}_{\max }$ from the surrogate model are shown as curving lines in figure 13. It is apparent that a range of $\left(G_{\text {IIc }}, \tau_{\text {IIc }}\right)$ pairs exist that would predict the outcome of the SLJ experiments. ${ }^{5}$ To complete the parameter mapping, the ranges of $G_{\text {IIc }}$ established by the ENF test are overlaid on the contour plot as vertical lines. The appropriate range of $\left(G_{\text {IIc }}, \tau_{\text {IIc }}\right)$ pairs for general use is the area within the two bands.

g It has been shown ${ }^{5}$ that the value of $\sigma_{\text {Ic }}$ also affects the maximum load in the SLJ test (to a lesser degree than $G_{\text {IIc }}$ and $\left.\tau_{\text {IIc }}\right)$. In this application of the conclusions of that paper, only $G_{\text {IIc }}$ and $\tau_{\text {IIc }}$ are allowed to vary due to the significant variability in the experimentally determined $G_{\mathrm{IIc}}$. The variability is likely to overwhelm the effects of $\sigma_{\text {Ic }}$. 


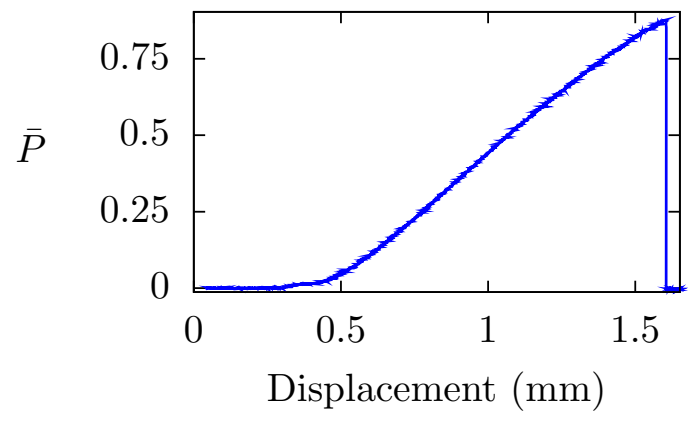

(a) $\mathrm{T}=20^{\circ} \mathrm{C}$

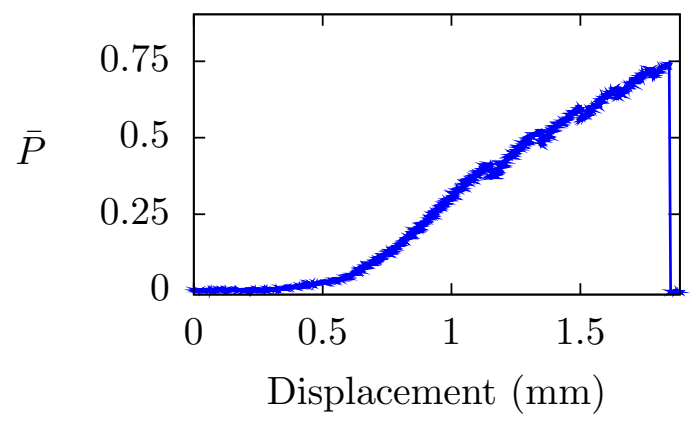

(c) $\mathrm{T}=250^{\circ} \mathrm{C}$

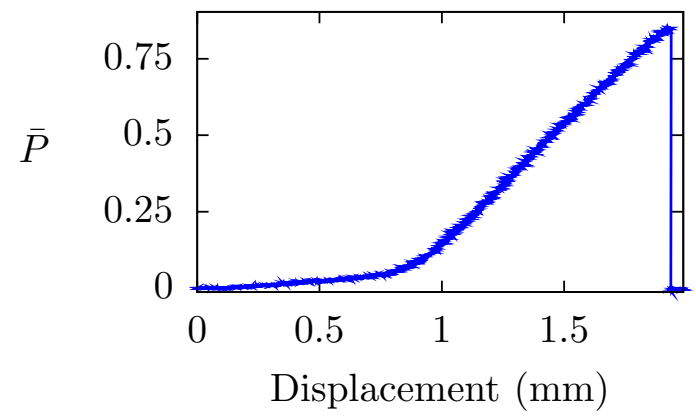

(b) $T=150{ }^{\circ} \mathrm{C}$

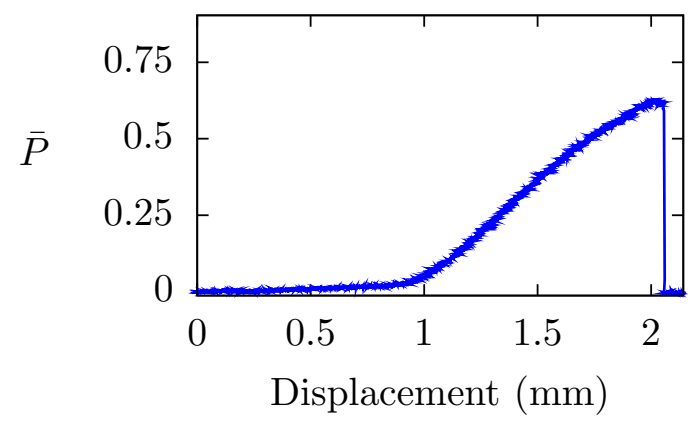

(d) $T=350{ }^{\circ} \mathrm{C}$

Figure 12: Typical normalized load-displacement for SLJ specimens 


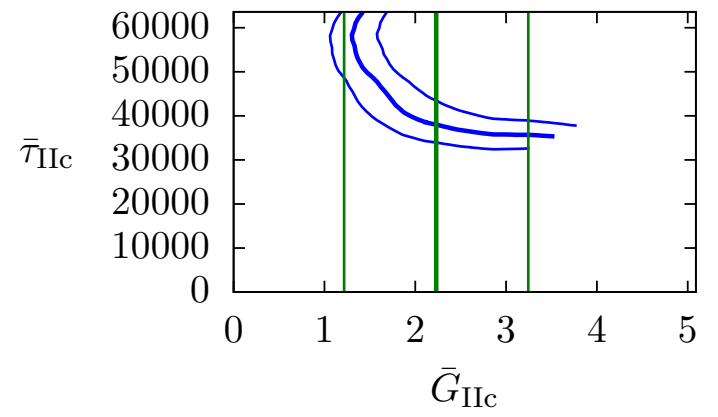

(a) $\mathrm{T}=20^{\circ} \mathrm{C}$

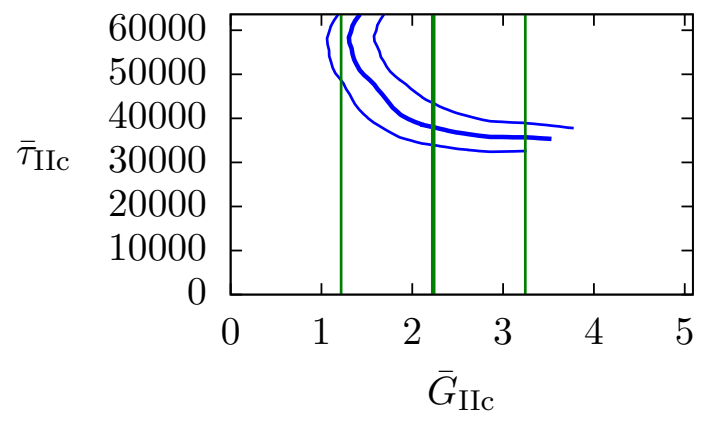

(c) $T=250{ }^{\circ} \mathrm{C}$

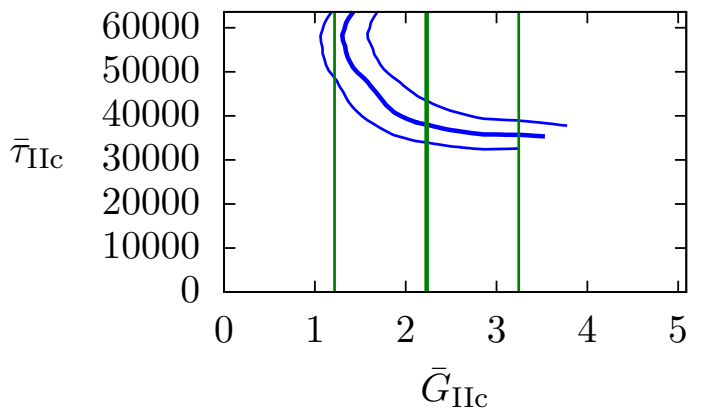

(b) $T=150^{\circ} \mathrm{C}$

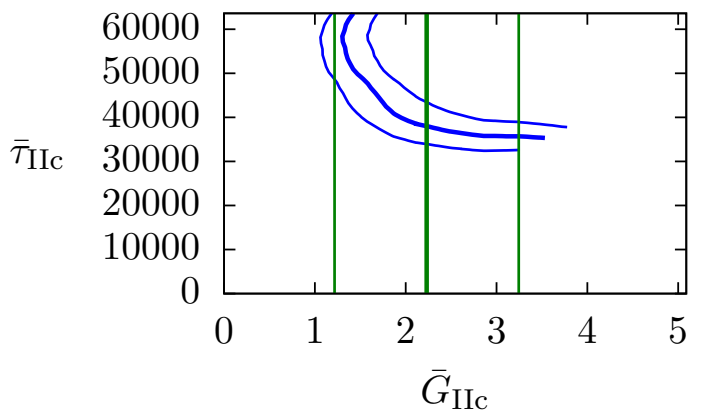

(d) $T=350^{\circ} \mathrm{C}$

Figure 13: Range of normalized material parameters for Mode II 


\section{Validation by a simple structural test}

A simple structural test (SST) was developed to explore the validity of the cohesive parameters. The experimental setup, shown in figure 15, was designed to subject the T650/AFR-PE4/FM680-1 adhesive system to a complex state of stress in three dimensions.

Due to its significant cost, a limited supply of T650/AFR-PE4/MF680-1 was available for structural level testing. To achieve the complex interfacial stress state without significant additional investment of materials, a stiffened plate specimen was designed via a series of $\mathrm{FE}$ models. In preliminary models using a 3D version of the DCZM element to predict cohesive failure, the SST was found to exhibit asymmetric adhesive fracture at the terminus of one of the stiffeners. (Mild asymmetry was included in the model due to manufacturing tolerances.) Therefore, the specimen was manufactured, tested, and subjected to in-depth analysis. A typical specimen geometry is shown in figure 14. The predicted failure mode and predicted location of failure were found to exist in the tested structure. Predicted out-of-plane deflections were qualitatively found to be similar to the deflections visualized with Moire fringes (figure 16).

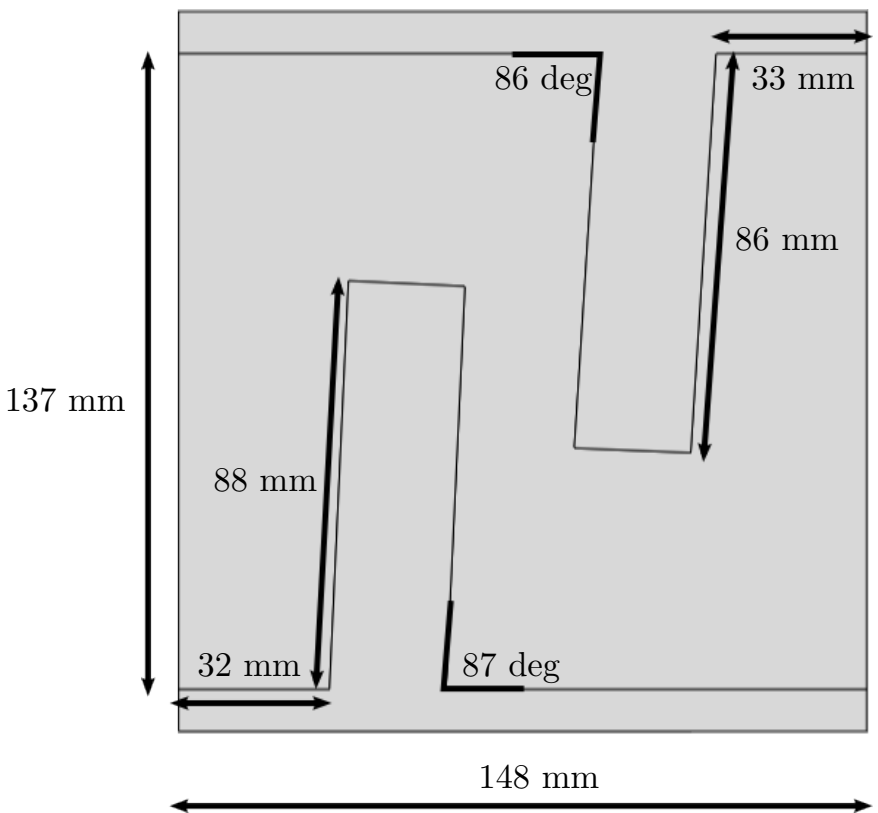

Figure 14: Typical dimensions of SST specimen as manufactured. The plate and stiffener each have nominal thickness $1.25 \mathrm{~mm}$.

\section{A. Comparison of model and experimental results}

The comparative outcome of the test and models is the load-displacement curve in axial loading of the plate (ie, buckling and post-buckling). A representative load-displacement curve for the SST is shown in figure 18. After machine settling, the initial loading was linear-elastic which continued until global buckling of the specimen. Shortly after global buckling, all three SST specimens exhibited decohesion at one of the stiffener terminus locations in the locations predicted by the FE model. The buckling mode was well predicted by the FE model as shown in figure 17.

The SST FE model was created in Abaqus ${ }^{\circledR}$ version 6.8. The plates are modeled with C3D8I (incom-

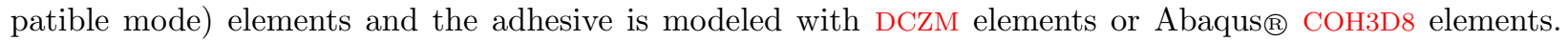
Thus, this paper reports the first direct comparison of the DCZM and COH3D8 elements. The cohesive parameters $\left(G_{\text {Ic }}, G_{\text {IIc }}, \sigma_{\text {Ic }}, \tau_{\text {IIc }}\right)$ established in coupon testing were used to enforce cohesion in each element. The input cards for the COH3D8 element were: "*cohesive section, response=traction separation, thickness=specified", "*damage initiation, criterion $=$ maxs", and "* damage evolution, type $=$ energy, mixed mode behavior=powerlaw, power $=1$, softening $=$ linear". These cards with the COH3D 8 element enforce a similar traction law to the DCZM element with a triangular traction law. 


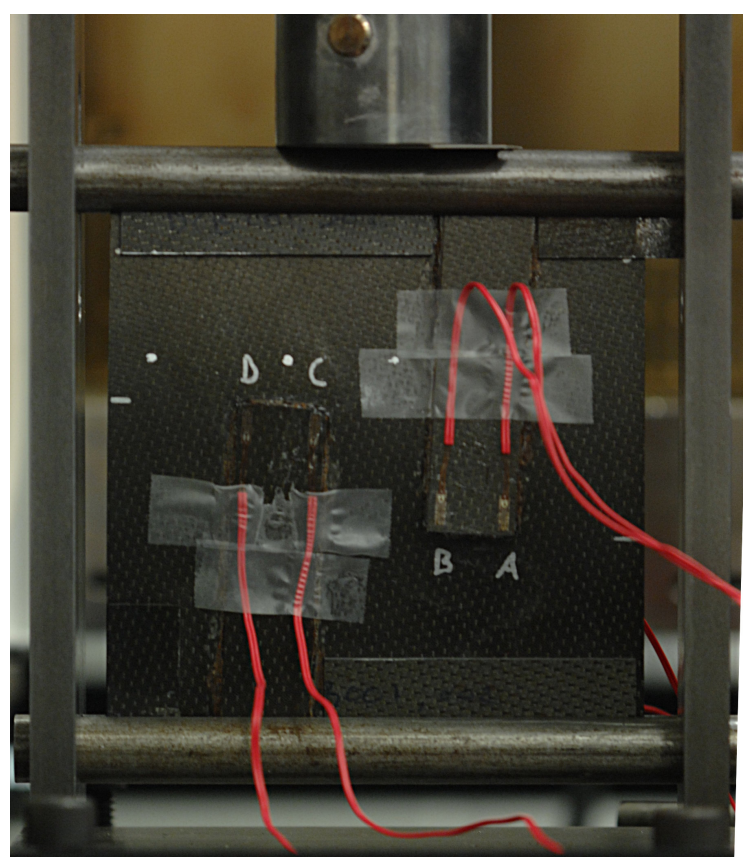

Figure 15: Typical buckled SST specimen
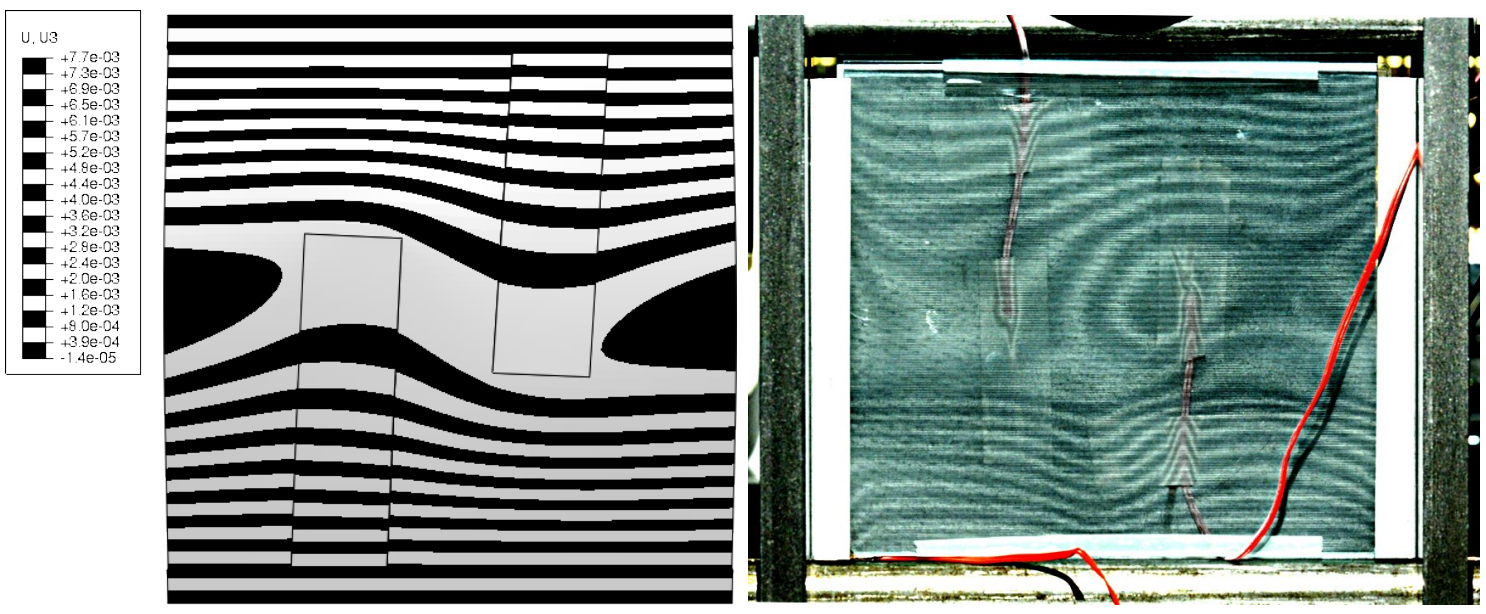

Figure 16: Typical Moire fringe patterns showing deflection of a buckled SST specimen. The gauges and gauge lead wires are also visible in the experiment. (The wires distort the pattern a small amount.) 


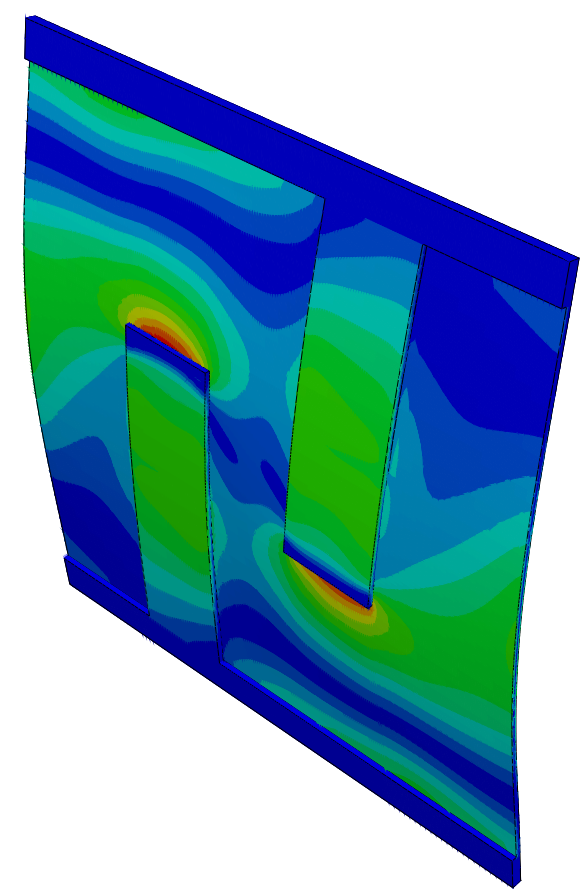

(a) Global view of buckled mode and von Mises equivalent stress

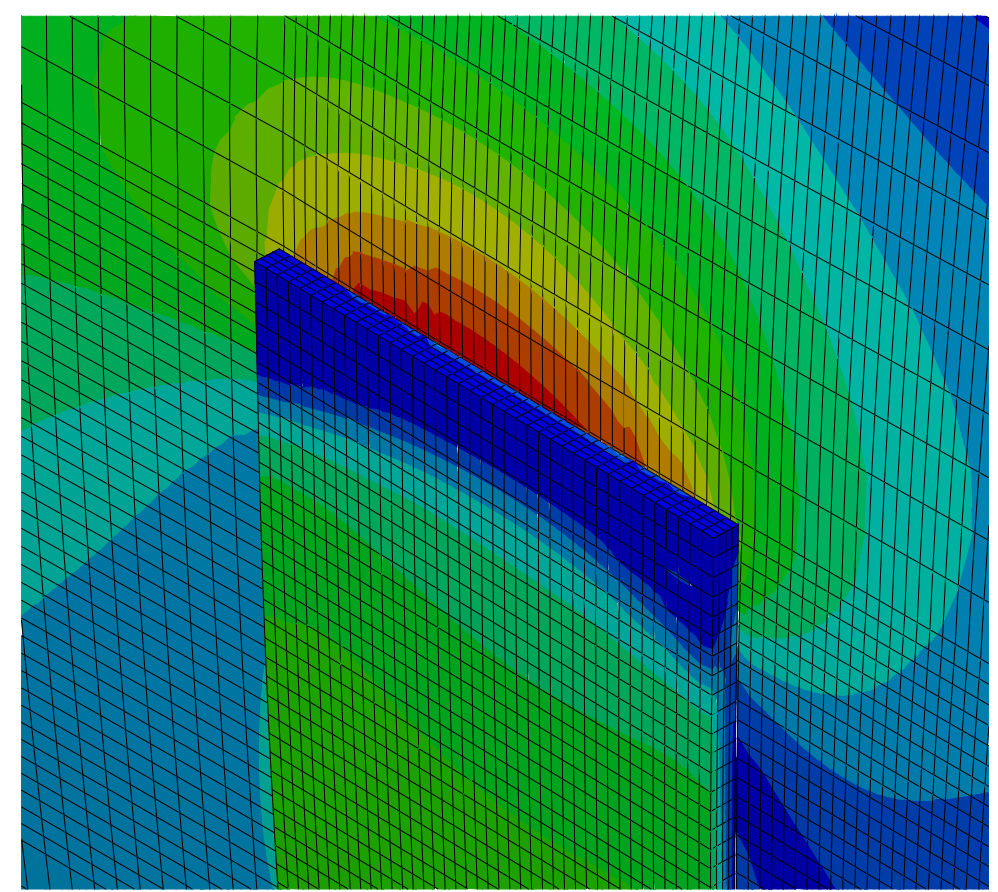

(b) Local view of stiffener terminus showing crack initiation. Crack propagation is imminent because the stiffener terminus has very low stress corresponding to the strain softening portion of the traction law.

Figure 17: Representative model of the SST

Each plate and stiffener has two elements through the thickness. Although two elements through the thickness are not adequate for "textbook" 8-node brick elements, the incompatible mode elements allow bending effects to be adequately captured. The DCZM or COH3D8 elements represent the adhesive and have direct nodal connectivity with the plate and stiffener elements. The material properties of the plates are withheld due to ITAR restrictions. The ends of the plate were constrained to translate and rotate as a rigid body to match the experimental constraints. A translational spring was included at one end to represent measured frame stiffness; displacement was enforced through the spring. A soft torsion spring and damper were included at each end. The torsion spring was required to calibrate the buckling load since frame stiffness affects the buckling load. The damper was used to improve convergence. The damping magnitude was selected to ensure it did not affect the global-loads. The number of nodes, elements, and degrees of freedom are listed in table 1. Non-linear geometry was assumed and allowed the post-buckling displacements to be computed. ${ }^{\mathrm{h}}$

Table 1: Approximate size of the SST FE model

\begin{tabular}{|l|r|}
\hline \hline Number of elements & 79000 \\
Number of user nodes & 101000 \\
Number of variables & 1360000 \\
\hline \hline
\end{tabular}

The experimental load-displacement and several model predictions based on nominal values of the measured cohesive parameters $\left(G_{\text {Ic }}, G_{\text {IIc }}, \sigma_{\text {Ic }}, \tau_{\text {IIc }}\right)$ are included in figure 18. Both the DCZM element (with triangular traction separation law) and the COH3D8 element over-predict the failure load and displacement at failure when nominal adhesive parameters are used. The load predictions are close, differing by $13 \%$

\footnotetext{
${ }^{\mathrm{h}}$ The symmetry of the lower bound analysis required a geometric perturbation to allow post-buckling to be modeled. This was completed using the "*buckle" and "*imperfection" keywords.
} 


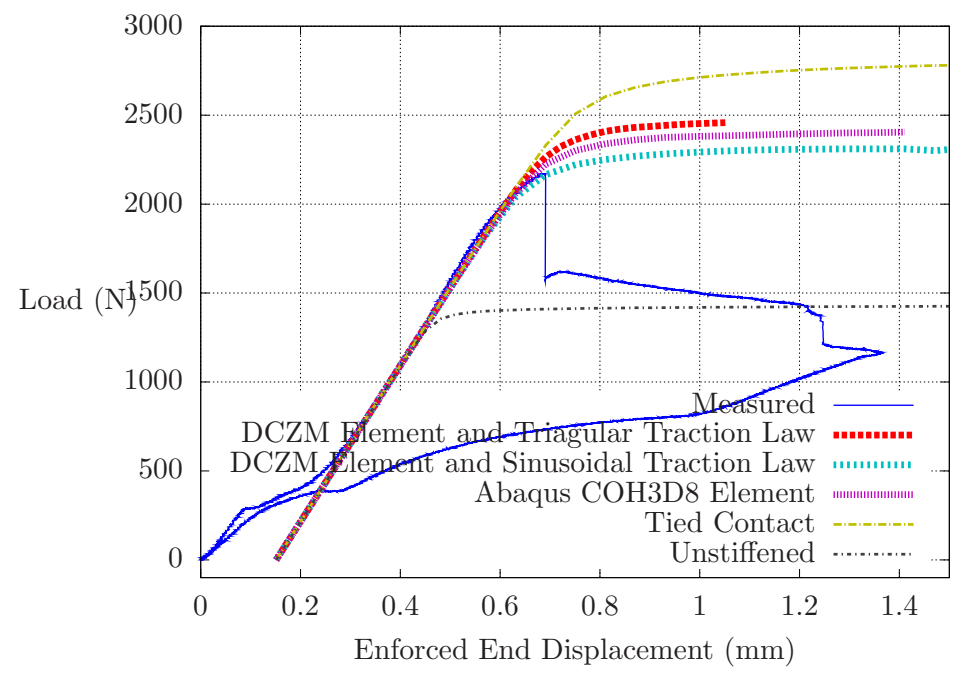

Figure 18: Load displacement curve

and $11 \%$ (this difference is affected by the torsional stiffness assumed for the edge restraints ${ }^{\mathrm{i}}$ ), however, the predicted displacement at failure is significantly larger than the experiment.

It is instructive to compare these predicted results to the load-displacement curve of a structure with the stiffeners rigidly bonded to the plate. This reference result, generated by the tied contact algorithms in Abaqus $\AA^{\circledR}$, provides an upper-bound reference path assuming no adhesive failure. A lower-bound is also plotted in figure 18 and corresponds to a model prediction with an unstiffened panel. All cohesive models fall between the upper and lower bounds.

Strain softening in the adhesive creates an instability in the equilibrium path. This softening and the non-linearities of contact and decohesion between the stiffener and plate surfaces cause significant difficulty in obtaining a converged solution. In all cases, the "*static, direct=no stop" keyword was used to force the solution to continue past convergence failures. Thus, the last point in the predicted load-displacement curve is not a reliable measure of failure. In post-processing the results, it is evident that decohesion is imminent. However, the solution fails ongoing convergence so no definitive fracture path is captured. The DCZM element (with triangular traction law) follows a similar equilibrium path to the COH3D8 element, however, the load path is slightly above that of the COH3D8 element. It is likely that slight differences in the stiffness between the DCZM element and the COH3D8 element result in slightly different buckling loads. The equilibrium paths are otherwise in agreement. In the DCZM element, as in the COH3D8 element, strain softening causes a trend to non-convergence so the definitive fracture path is not captured.

It has been shown that a sinusoidally shaped traction law, in aggregate, converges more quickly and more reliably than a traction law with stiffness discontinuities ${ }^{6}$ (the sinusoidal law has smooth, continuous derivatives). Thus, the DCZM element was used with a sinusoidal traction law (shown in figure 19) to predict the stiffened panel response. Since the sinusoidal traction law has a lower initial stiffness than the triangular law (assuming the same $G_{\mathrm{c}}$ and $\sigma_{\mathrm{c}}$ ), the model based on the sinusoidal law buckles earlier than the model based on the triangular law. Thus, the predicted failure load is within $7 \%$ of the experiment. As was previously reported, ${ }^{6}$ convergence was better when the sinusoidal traction law was used. However, convergence issues were not overcome. Thus, the unstable fracture load path (with a significant drop in load) was not captured.

\section{B. Comments regarding the proposed validation method}

The proposed simple structural test was a challenging validation test because failure is not gradual. Once fracture initiates, the problem becomes unstable. Unstable equilibrium problems have been tackled before by the authors. ${ }^{5}$ In initial models prior to manufacturing of the specimens and test setup, it appeared

\footnotetext{
${ }^{i}$ Since the assumed torsional stiffness of the constraints affects the buckling load, the equilibrium path was aligned to the experimental path. The alignment was based on the sinusoidal traction law and fixed for the other traction laws.
} 


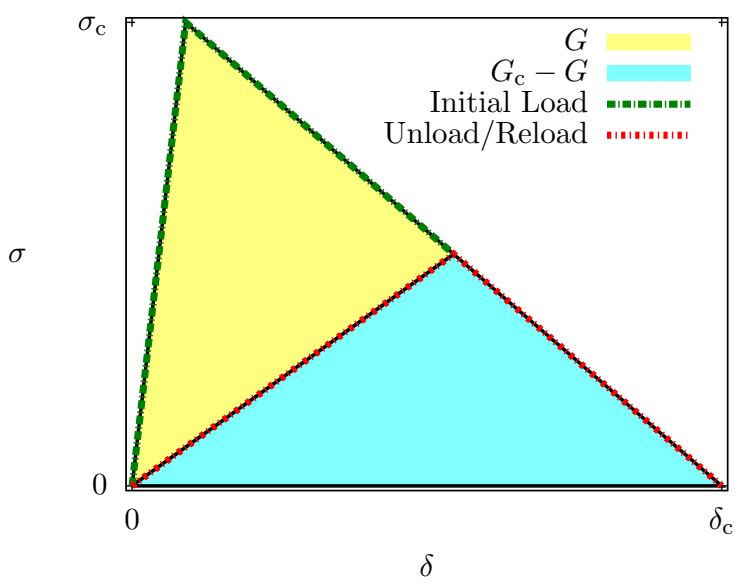

Figure 19: The sinusoidal traction separation law. This law tends to improve model convergence and is used for comparison.

the test would provide a reliable method of validation. In hindsight, the model convergence issues masked the instabilities present in the test configuration. Figure 20 shows the predicted load-displacement curves when single cohesive parameters are reduced by $50 \%$ relative to the nominal value. When the $G_{\mathrm{c}}$ values are reduced, there is almost no-difference in the load-displacement path. This is because the postbuckled state of the panel leads to interfacial tractions that drive failure quickly and unstably unless the fracture toughness values are exceedingly high (approaching the perfectly bonded stiffeners). Thus, this problem configuration cannot be reliably used for validation of $G_{\mathrm{c}}$ values. This result suggests the use of explicit finite element methods for solving problems when unstable fracture is evident. When the $\sigma_{\mathrm{c}}$ values are reduced by $50 \%$, the cohesive stiffness changes and a small change in buckling load is observed. However, this small change is within the margin of error of the assumed torsional stiffness of the constraints.

The test proposed in this paper is not ideal for validation of a set of cohesive parameters when implicit cohesive methods are used. It is currently being re-analyzed using an explicit version of the DCZM element. Results will be reported at subsequent SDM meetings.

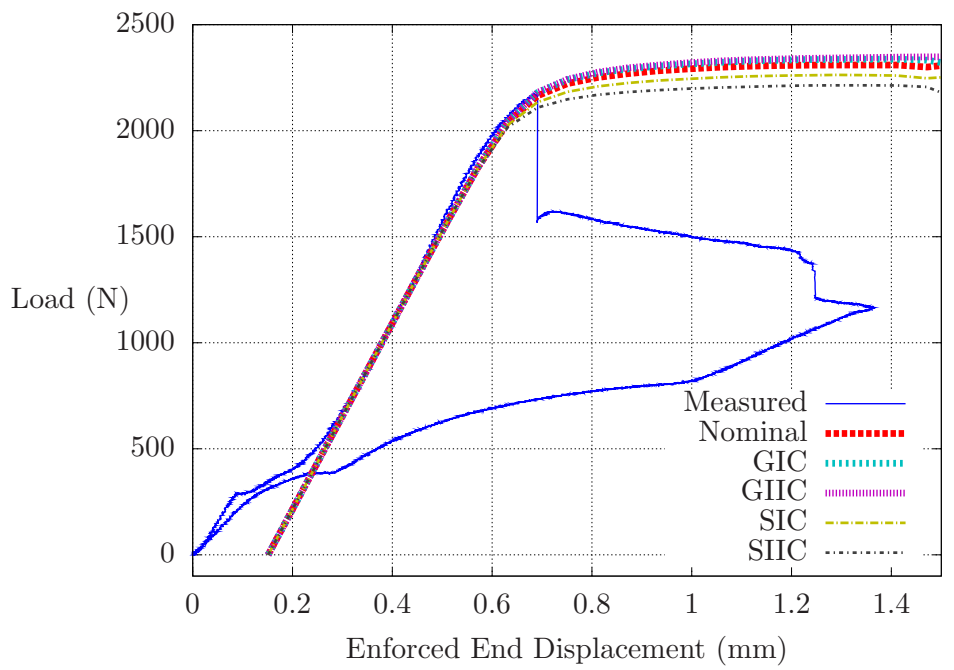

Figure 20: Load displacement curves for a 50\% reduction (vs nominal) in the listed cohesive parameter 


\section{Comments regarding the validity of the cohesive parameters}

Despite the problems with the validation test, the predicted displacements at failure are larger than measured values. Therefore, an open question remains regarding the validity of the cohesive parameters. Since experimental failure occurs earlier than the models predict, it is possible that the adhesive parameters developed in coupon testing do not correspond to the adhesive in the structural test. There are reasons why the coupon-level parameters may not be suited to the structural level test. For example, the coupon-level toughness tests (and their corresponding parameters $G_{\text {Ic }}$ and $G_{\text {IIc }}$ ) were determined after a natural crack was initiated. Unfortunately, no natural crack could be initiated in the SST specimen prior to testing. This could lead to a discrepancy in the effective adhesive properties between coupon-level and structural specimens. Another possible (and related) source of discrepancy is the R-curve. ${ }^{10}$ If an R-curve exists such that the toughness values scale with crack length prior to leveling off, then the SST specimen would fail while in the low toughness domain of the R-curve. Since this domain was not measured in coupon tests, the SST experiments would fail at loads below the model predictions. Thus, in hindsight, the adhesive properties tested by the proposed SST may not correspond well to those of the coupon-level tests. An improved validation test would allow a pre-crack to be initiated between the stiffener and the panel, prior to the experiment. Coupon level and validation experiments should have similar crack tip environments. An analysis that incorporates an explicit solver is currently being carried out to obtain insight into the unstable fracture event observed in the tests.

\section{Conclusion}

A simple structural test has been proposed to validate a set of cohesive parameters in a complex stress state. The stress state was induced by combined shear and normal stresses at the terminus of a plate stiffener when the plate was subjected to axial (wide panel) buckling. The test was found to be incapable of validation due to modeling and experimental complexities associated with buckling and also due to cohesive instabilities and their interactions. The instabilities point to the need for an explicit solver for unstable fracture problems.

A four parameter traction law $\left(G_{\text {Ic }}, \sigma_{\text {Ic }}, G_{\text {IIc }}\right.$, and $\left.\tau_{\text {IIc }}\right)$ has been developed for a T650/AFR-PE-4/FM6801 material system. The traction law was used to predict the failure mode and load of the simple structural test specimens, however, the displacement at failure was not well predicted. It was hypothesized that the validation test and coupon level tests have different crack-tip environments and thus may not be well suited for comparison. Currently, the cohesive parameters can be used with the DCZM or Abaqus ${ }^{\circ}$ COH3D8 finite element over the range of $20-350{ }^{\circ} \mathrm{C}$, however, the results must be carefully evaluated to determine if the coupon level tests adequately represent the cohesive environment to be modeled. Results from an analysis that uses an explicit solver are presently being analyzed and will be reported at future SDM conferences. In addition to the structural level validation attempt, the experiments that led to the cohesive zone parameters were summarized.

\section{Acknowledgments}

This work was supported by the Space Vehicle Technology Institute under grant NCC3-989 jointly funded by NASA and the Department of Defense. It was managed within the NASA Constellation University Institutes Project, with Claudia Meyer as the project manager and H. Kevin Rivers \& Stanley Smeltzer as the project monitors.

\section{References}

\footnotetext{
${ }^{1}$ Gustafson, P. A. and Waas, A. M., "T650/AFR-PE-4/FM680-1 Mode I Critical Energy Release Rate at High Temperatures: Experiments and Numerical Models," Proceedings of the AIAA/ASME/ASCE/AHS/ASC 48th Structures, Structural Dynamics, and Materials Conference, Apr 23-26 2007, Honolulu HI, No. 2007-2305, American Institute of Aeronautics and Astronautics, 2007.

${ }^{2}$ Simulia, Inc, Abaqus User Manual v6.8, Electronic Version, 2009.

${ }^{3}$ Whitley, K. S. and Collins, T. J., "Mechanical properties of T650-35/AFR-PE-4 at elevated temperatures for lightweight aeroshell designs," Proceedings of the AIAA/ASME/ASCE/AHS/ASC 47th Structures, Structural Dynamics, and Materials Conference, May 1-4 2006, Newport RI, No. 2006-2202, American Institute of Aeronautics and Astronautics, 2006.

${ }^{4}$ Gustafson, P. A., Analytical and Experimental Methods for Adhesively Bonded Joints Subjected to High Temperatures,
} 
Ph.D. thesis, University of Michigan, 2008.

${ }^{5}$ Gustafson, P. A. and Waas, A. M., "The influence of adhesive constitutive parameters in cohesive zone finite element models of adhesively bonded joints," International Journal of Solids and Structures, Vol. 46, No. 10, 2009, pp. 2201-2215.

${ }^{6}$ Gustafson, P. A. and Waas, A. M., "Efficient and Robust Traction Laws for the Modeling of Adhesively Bonded Joints," Proceedings of the AIAA/ASME/ASCE/AHS/ASC 49th Structures, Structural Dynamics, and Materials Conference, Apr 7-10 2008, Schaumburg, IL, No. 2008-1847, American Institute of Aeronautics and Astronautics, 2008.

${ }^{7}$ Davidson, B. and Sun, X., "Geometry and Data Reduction Recommendations for a Standardized End Notched Flexure Test for Unidirectional Composites," Journal Of ASTM International, Vol. 3, No. 9, 2006, pp. 1-19.

${ }^{8}$ Sun, C., Fracture of plastically-deforming, adhesively-bonded structures: experimental and numerical studies, Ph.D. thesis, University of Michigan, 2007.

${ }^{9}$ Davidson, B., "Towards an ASTM Standardized Test for Determining $G_{\text {IIc }}$ of Unidirectional Laminated Polymeric Matrix Composites," Proceedings of the American Society of Composites 21st Annual Technical Conference, American Society of Composites, Sept 2006.

${ }^{10}$ Anderson, T. L., Fracture mechanics: fundamentals and applications, CRC Press, 2005. 